\title{
De Wajong-werkregeling: kanttekeningen bij voorgenomen wijzigingen
}

\author{
J.J.M. Besseling
}

Het aantal jongeren dat jaarlijks een beroep doet op de Wajong, groeit sterk en is de afgelopen vijf jaar verdubbeld. Per I april 2008 ontvingen I70.000 mensen een Wajong-uitkering. In 2007 zijn ruim I5.000 Wajong-uitkeringen toegekend en UWV verwacht in 2008 ruim I6.000 Wajonguitkeringen toe te kennen. In 2007 komt van alle I8-jarigen I op de I6 op I8-jarige leeftijd of later in aanmerking voor een Wajong-uitkering, wat overeenkomt met een Wajong-incidentie van $6,2 \% .{ }^{2}$ Ramingen wijzen op een groei tot mogelijk 450 duizend Wajongers in 2050. De kosten lopen dan op van bijna 2 miljard nu naar ruim 5 miljard in 2050.

De toename van het aantal Wajong-toekenningen staat niet op zichzelf. Alle voorzieningen waarvoor gegevens over meerdere jaren beschikbaar zijn (speciaal onderwijs en 'rugzakjes', jeugdzorg, TOG (regeling Tegemoetkoming Onderhoudskosten thuiswonende zorgafhankelijke Gehandicapte kinderen), vervoersvoorzieningen en Wajong) laten een substantiële groei zien die beduidend groter is dan de geringe groei van het aantal jongeren. ${ }^{3}$ De groei in het speciaal onderwijs van de afgelopen jaren zal tot een verdere stijging leiden van het aantal Wajong-toekenningen in de komende jaren. Ongeveer de helft van de leerlingen van praktijkonderwijs en voortgezet speciaal onderwijs stromen uiteindelijk de Wajong in.

Voor de groei zijn zeer veel, overwegend nietkwantificeerbare en onbewezen verklaringen zoals het complexer worden van de samenleving: Aan jongeren worden meer en andere eisen gesteld dan vroeger, niet alleen in het onderwijs maar ook in arbeid; veelal cognitieve of sociale eisen waar met name jongeren met gedragsproblemen niet zonder aanvullende hulp/voorzieningen aan kunnen voldoen.

Er werd echter in (epidemiologische) studies geen toename van sociaal-medische problematiek gevonden die de sterke groei van het voorzieningengebruik zou kunnen verklaren. Soms zijn er wel duidelijke redenen voor een toename: de regeling is nieuw en wordt door voorlichting en mond-op-mondreclame steeds bekender zoals bij rugzakje en de TOG. Of de doelgroep is de afge-
SAMENVATTING

Onlangs heeft het kabinet de contouren van zijn plannen met de Wajong geschetst. ${ }^{\mathrm{I}}$ In dit artikel bespreken we de aanleiding voor de plannen en de plannen zelf. Vervolgens gaan we in op een aantal voorgenomen wijzigingen ten opzichte van het bestaande beleid of de praktijk, namelijk:

I de uitbreiding van de huidige claimbeoordeling met een beoordeling van het kunnen én willen werken en het belang van de context om het arbeidsvermogen van een jonggehandicapte te kunnen beoordelen;

I de kabinetsplannen om UWV werk aan te laten bieden aan de Wajonger;

I de voorgestelde wijzigingen in financiële prikkels voor Wajongers om te gaan werken;

I het feit dat in de Wajong-werkregeling arbeid verplichtend wordt opgelegd aan de Wajonger ook als dat arbeid is onder het minimumloon.

De voorgestelde wijzigingen zijn zo ingrijpend dat een fundamentele discussie wenselijk is over de onderliggende normen en waarden van onze sociale zekerheid en over de relatie tussen het SER-advies 'Meedoen zonder beperkingen' en het kabinetsvoorstel.

lopen jaren verbreed of anders gedefinieerd ((Voortgezet) Speciaal Onderwijs, rugzakje, TOG). Er zijn geen gegevens beschikbaar over samenloop van het gebruik van regelingen of van opeenvolgend gebruik van diverse regelingen. Daardoor kan niet met zekerheid gesteld worden dat er sprake is van een glijbaaneffect en jongeren met een beperking bijna automatisch van de ene voorziening naar de andere gaan.

In oktober 2005 werkte $26 \%$ van alle Wajongers waarvan $17 \%$ in sociale werkvoorzieningsverband (SW) en $9 \%$ regulier. ${ }^{4}$ Op jongere leeftijd (tot 25 jaar) is de arbeidsparticipatie met 32\% het grootst waarvan $19 \%$ in reguliere banen en I $3 \%$ in SW-verband. In oudere leeftijdsgroepen daalt de arbeidsparticipatie tot $22 \%$ onder Wajongers van 45-jarige leeftijd of ouder, van wie meer dan negen van de tien personen werken in SW-verband. ${ }^{5}$

Het moge duidelijk zijn dat er meer Wajongers met arbeidsmogelijkheden zijn dan degenen die werken. UWV-onderzoekers komen in hun dos-
WAJONG,

CLAIMBEOORDELING,

ONBENUT

ARBEIDSVERMOGEN 
sieronderzoek naar de nieuwe Wajong-instroom 2002-2006 onder de 27 jaar tot een participatiepotentieel van iets meer dan 50\%: in 2006 werkt $29 \%$ van deze Wajongers, I $2 \%$ is op weg of wordt begeleid naar loonvormende arbeid en I $2 \%$ is (nog) niet op weg naar betaalde arbeid. ${ }^{6}$ Van alle personen aan wie een Wajong-uitkering toegekend is, lijkt I op de 4 à 5 niet te werken maar wel over arbeidsmogelijkheden te beschikken. ${ }^{5}$

Recent is het inzicht ontstaan dat voor een substantieel deel van de Wajongers het belangrijkste knelpunt niet lijkt te zijn om de stap naar een arbeidsplek te maken maar om die plek te behouden. Circa een derde van de Wajongers valt binnen één jaar na het verkrijgen van een baan uit of vindt geen aansluiting tussen stage en werk. ${ }^{6}$ Ook de helft van de banen die begeleid worden door een jobcoach, zijn na zes maanden beëindigd. ${ }^{7}$ De arbeidsparticipatie van Wajongers daalt in de oudere leeftijdsgroepen en verschuift van werken op de reguliere arbeidsmarkt naar werken in SW-verband. ${ }^{5}$ Het is niet bekend in welke mate dat effect veroorzaakt wordt doordat de Wajongers uitvallen in reguliere arbeid en op latere leeftijd opteren voor arbeid in SW-verband.

\section{KABINETSPLANNEN}

Het kabinet vindt het onaanvaardbaar dat steeds meer jongeren op een zijspoor raken en niet meer meedoen in de samenleving, terwijl ze daar wel mogelijkheden voor hebben. Het kabinet is voornemens om de Wajong aan te passen; vanaf 2010 zijn er twee keuringsmomenten: een keuring bij de aanvraag van de Wajong en een beoordeling in principe op 27 jaar. Jongeren bij wie bij de eerste keuring al duidelijk is dat ze nooit kunnen werken, krijgen een Wajong-uitkering op het niveau van personen die volledig arbeidsongeschikt zijn (75\% van het minimumloon). Jongeren die mogelijkheden hebben om te werken, krijgen ondersteuning en begeleiding bij het vinden en behouden van werk bij reguliere werkgevers. Inko-

I Ongeveer 20\% van de Wajongers beschikt over onbenut arbeidsvermogen.

I De voorgestelde Wajong-werkregeling verplicht de jonggehandicapte tot arbeidsdeelname, ook als dat arbeid is onder minimumloonwaarde.

I De claimbeoordeling wordt uitgebreid met de vraag of de Wajonger arbeidsvermogen heeft én voldoende inspanningen verricht om te gaan werken. mensondersteuning is alleen aan de orde in aanvulling op het inkomen uit werk of als er buiten schuld geen werk is.

Jongeren die bij de voorlopige keuring (gedeeltelijk) mogelijkheden hebben om te werken, maar niet zelfstandig $75 \%$ van het minimumloon kunnen verdienen, komen in de nieuwe werkregeling Wajong terecht. Deze regeling beoogt hen maximaal te ondersteunen bij het vinden en behouden van werk. Zij krijgen een participatieplan waarin hun rechten en plichten staan. Een werk- of leeraanbod moeten ze accepteren. Uitgangspunt is dat Wajongers 20\% van het minimumloon zelf kunnen verdienen. In aanvulling daarop kunnen ze inkomensondersteuning krijgen met een uitkeringspercentage van $75 \%$. Dit is ook het geval als betrokkene buiten zijn schuld geen werk heeft of het aangeboden werk geen inkomen van $20 \%$ van het minimumloon kan opleveren.

Voor Wajongers die werken, zal boven de genoemde drempel van 20\% meer werken meer lonen. Van elke extra verdiende euro aan loon, behoudt de Wajonger de helft tot een maximum van I00\% minimumloon. Studerende jonggehandicapten krijgen studiefinanciering en kunnen een aanvulling aanvragen van $25 \%$ minimumloon.

Om het voor werkgevers aantrekkelijker te maken om Wajongers in dienst te nemen, komt er vanaf oktober 2008 een loket dat de administratieve rompslomp zo veel mogelijk uit handen neemt en worden de werkplekaanpassingen voortaan volledig vergoed.

\section{BIJ BEOORDELING VAN WAJONGERS WORDT CONTEXT BELANGRIJKER}

Met de nieuwe plannen van het kabinet verandert de Wajong-claimbeoordeling door UWV. Juist de beoordeling van de toekomstige mogelijkheden is een ingewikkeld vraagstuk. Bij de eerste beoordeling rondom het $\mathrm{s} 8 \mathrm{e}$ jaar gaat het immers om jongeren die zich per definitie nog kunnen ontwikkelen, maar tot welk niveau is de vraag. Dit geeft de Wajong-beoordeling een ander karakter dan de gemiddelde WIA-beoordeling. Arbeid en arbeidsongeschiktheid zijn daarbij geen vaststaande concepten maar worden mede cultureel of sociaaleconomisch bepaald. De arbeidsperspectieven van Wajongers zijn ook afhankelijk van hoeveel inspanningen en financiën men ervoor overheeft. Zo zou in sommige staten in de VS een I-op-I-begeleiding mogelijk zijn en soms ook begeleid leren bijvoorbeeld na drie jaar uitval. 
Of een Wajonger arbeidsperspectief heeft, is van vele factoren afhankelijk. Slechts zelden is één factor doorslaggevend voor de prognose van het arbeidsperspectief van een Wajonger. Veel factoren liggen in de omgeving of context van de jongere. Experts geven aan dat een goede contextanalyse een van de belangrijkste voorwaarden is voor een succesvolle ontwikkeling van de Wajonger. ${ }^{5}$ De capaciteit van een Wajonger wordt niet alleen bepaald door een combinatie van competenties (kennis en vaardigheden) en mogelijkheden tot functioneren (ruwweg de FML) maar ook door gedrag en de mogelijkheden die er zijn om gedrag en/of competenties te ontwikkelen. Voor de bepaling van participatiemogelijkheden van Wajongers, zijn dus niet alleen de elementen van de persoon zelf van belang maar ook de omgeving waarin de cliënt zal (kunnen) participeren. De mogelijkheden om bepaalde interventies toe te passen en de effectiviteit ervan op het arbeidsperspectief van de Wajonger zijn sterk afhankelijk van zijn/haar omgeving: in sommige omgevingen zullen bepaalde cliënten floreren en andere juist achteruitgaan.

\section{DE ARBEIDSMARKT KOMT TERUG IN DE CLAIMBEOORDELING WAJONG}

Met de invoering van de stelselherziening in I987 is expliciet beoogd om de feitelijke kansen op de arbeidsmarkt buiten beschouwing te laten bij de arbeidsongeschiktheidsbeoordeling en het recht op een arbeidsongeschiktheidsuitkering: de arbeidsongeschiktheidsbeoordeling is een theoretische beoordeling van een individu en abstraheert van de kans dat betrokkene zijn/haar verdiencapaciteit ook zal kunnen en/of willen realiseren op de arbeidsmarkt.

UWV blijft weliswaar beoordelen of de theoretische verdiencapaciteit van betrokkene door ziekte of gebrek minder is dan $75 \%$ van het minimumloon en er dus sprake is van arbeidsongeschiktheid voor de Wajong. Maar in de tweede stap van de beoordeling gaat de arbeidsmarkt wel een rol spelen. Volgens de kabinetsplannen krijgt UWV de taak om aan jonggehandicapten met arbeidsperspectief in de Wajong-werkregeling een baan of een leer(werk)traject aan te bieden. De jongere loopt bij weigering het risico op volledige inhouding van zijn inkomensondersteuning. De sanctie lijkt gezien de formulering ('Inkomensondersteuning is alleen aan de orde in aanvulling op het inkomen uit werk of als er buiten schuld geen werk is.') verder te kunnen gaan dan de feitelijke loonwaarde die hij/zij zou kunnen realiseren in die arbeid. Ook als zijn/haar loonwaarde een deel van het minimumloon bedraagt en de jongere dus slechts beperkt in staat is om de financiële schade voor de samenleving te beperken, lijkt het kabinet voornemens de jongere elke vorm van inkomensondersteuning binnen de Wajong-werkregeling te onthouden.

WELKE ARBEID ZAL

UWV PASSEND ACHTEN?

Als UWV vaststelt dat de Wajonger nu of in de toekomst in staat is tot arbeid met enige loonwaarde, stelt UWV een participatieplan op. Gericht wordt op arbeid bij reguliere werkgevers. In de kabinetsplannen biedt UWV de banen aan aan de Wajongers in de werkregeling. Het kabinetsplan opteert nadrukkelijk voor banen bij reguliere werkgevers en niet voor functies binnen een nieuwe 'publieke werkvoorziening' door UWV. Echter niet UWV biedt een baan aan, maar een werkgever. Dit is niet alleen een semantische opmerking. In de interactie tussen werkgever en jonggehandicapte zal een potentiële aanbieding wel of niet leiden tot concrete vacature-invulling door deze jonggehandicapte. Dit plaatst UWV op afstand, en plaatst het beoordelingsproces of een Wajonger door eigen schuld buiten arbeid staat, in het zelfde perspectief als de handhavingstaak van UWV in WW.

Er zijn nadrukkelijk ook verschillen met een werkzoekende WW'er die verplicht is om afhankelijk van de duur van de werkloosheid passend of gangbare arbeid te accepteren. Voor de Wajongwerkregeling is 'arbeid' nog niet nader ingevuld en ook niet afgestemd met de huidige indicatiecriteria voor de WSW en criteria voor 'arbeidsmatige dagbesteding' binnen AWBZ-gefinancierde zorginstellingen. Vooralsnog geeft het kabinet aan dat UWV ook arbeid kan aanbieden met een loonwaarde onder $20 \%$ van het minimumloon (ML). Op dit moment hanteren re-integratiebedrijven impliciet of expliciet een ondergrens voor reguliere arbeid waar ze Wajongers naartoe begeleiden. Eén van de geraadpleegde re-integratiebedrijven gaf aan dat re-integratie (bijna) niet haalbaar is bij een verdiencapaciteit van minder dan 40\% ML. ${ }^{5}$ Hun streven is dat cliënten die het re-integratietraject naar werk doorlopen, uitkomen op ongeveer 60-70\% verdiencapaciteit. Ook de indicatie voor de WSW hanteert een ondergrens. De cliënt moet bijvoorbeeld minstens één uur achter elkaar kunnen werken en minimaal twee verschillende functies kunnen vervullen met een ondergrens van I $5 \%$ van het minimumloon als minimale verdienmogelijkheid. Echter, naar verwachting zullen slechts weinig werkgevers bereid zijn om Wajon- 
gers regulier aan te nemen als ze zo'n beperkte economische bijdrage leveren aan de bedrijfsvoering.

In dit verband is ook van belang dat zicht is op grenzen wanneer nog sprake kan zijn van arbeid met een verplichtend karakter. Dat betreft enerzijds de kwaliteitseisen aan arbeid in relatie tot de mogelijkheden van de Wajonger zelf en anderzijds speelt bij een substantieel deel van deze doelgroep de vraag in hoeverre arbeidsparticipatie niet ten koste gaat van de toch al veelal beperkte bestaande maatschappelijke participatiemogelijkheden.

\section{ARBEID ONDER MINIMUMLOON}

Het kabinetsvoorstel is dat Wajongers op straffe van sancties verplicht zijn om werk te accepteren ook als daarmee niet het minimumloon verdiend kan worden. Voor Wajongers bestaat al geruime tijd de mogelijkheid dat werkgevers in bepaalde gevallen minder betalen dan het minimumloon (artikel 59a en artikel 76b lid I Wajong ${ }^{8}$ ). Deze loondispensatie is alleen mogelijk indien de arbeidsprestatie van de jonggehandicapte werknemer ten gevolge van ziekte of gebrek duidelijk minder is dan de arbeidsprestatie die een geldelijke beloning van het voor hem/haar geldend minimumloon rechtvaardigt. UWV kan op verzoek van betrokken werkgever of werknemer de hoogte van de beloning voor de verrichte arbeid verminderen, waarbij UWV voor een 'duidelijk verminderde arbeidsprestatie’ een productiviteitsvermindering van minstens $25 \%$ verstaat. De kabinetsplannen wekken de indruk dat het kabinet voornemens is om werkgevers voor Wajongers functies of takenpakketten te laten creëren waarmee niet (altijd) het minimumloon verdiend kan worden en deze werkzaamheden verplichtend op te leggen aan jonggehandicapten in de werkregeling.

Hier lijkt sprake van een trendbreuk en van een fundamentele stap op weg naar het loslaten van de beschermingsfunctie van de Wet minimumloon. Overigens lijkt de wetgever dit beleid breder te willen trekken gezien het voornemen om bijstandsgerechtigden te kunnen verplichten (reguliere) arbeid te verrichten met behoud van WWB-uitkering in de zogeheten participatiebanen. Een onderwerp dat een bredere en fundamentelere discussie verdient dan het tot nu toe gekregen heeft. ${ }^{9}$

\section{ARBEID GAAT ANDERS LONEN}

Het kabinet stelt voor om de huidige bijverdienregeling te vervangen. In artikel 50 Wajong is momenteel geregeld dat gedurende 5 jaar de inkomsten uit arbeid geanticumuleerd worden op de Wajong-uitkering. ${ }^{8}$ Op basis van de inkomsten vindt een fictieve schatting plaats door UWV en wordt zo nodig het uitkeringspercentage aangepast. Door het trapsgewijze systeem van berekening van de resterende Wajong-uitkering kan bij parttimers een uur meer werken leiden tot een forse afname van het inkomen. ${ }^{\text {Io }}$

Het kabinet vervangt de stapsgewijze aanpassing van de uitkering door een glijdende schaal. In tegenstelling tot de huidige situatie zijn de eerste inkomsten tot $20 \%$ van het minimumloon niet meer 'vrij' maar worden juist verrekend met de uitkering. Vervolgens mag de Wajonger de helft van zijn inkomsten houden tot een maximum van 100\% ML. Als betrokkene 70\% van het ML verdient, vult de inkomensondersteuning het inkomen aan tot Ioo\% van het ML. Als betrokkene tussen de $70 \%$ en I00\% van het ML verdient, stijgt zijn totale inkomen niet verder en blijft het inkomen Ioo\% van het ML.

De vraag is welke beleidstheorie de nieuwe bijverdienregeling rechtvaardigt. Met het invoeren van de nieuwe bijverdienregeling beloont het kabinet de arbeidsparticipatie naar rato van de loonwaarde die de Wajonger realiseert. De huidige bijverdienregeling beloont de Wajonger als zijn/haar arbeidsparticipatie in verhouding is tot de mogelijkheden waarover de Wajonger beschikt. Veelal zijn Wajongers niet in staat om een arbeidsprestatie te leveren ter waarde van het ML, maar is hun arbeidsparticipatie wel naar hun vermogen. Ook dat zou, zeker bij de huidige kabinetssamenstelling, nog steeds een criterium kunnen zijn voor de aanvullende inkomensondersteuning.

In het kabinetsvoornemen is het daarnaast opmerkelijk dat voor een Wajonger arbeid alleen loont in het traject tussen 20 en $70 \%$ van het minimumloon. Tot 20\% van het ML loont arbeid niet voor een Wajonger en ook boven 70\% loont het meer gaan verdienen niet. Logischer zou zijn om de Wajonger te prikkelen om zoveel verdiensten te realiseren dat betrokkene niet meer afhankelijk is van de inkomensondersteuning, dus het ML of meer verdient. Nu stopt die prikkel op het moment dat betrokkene 70\% van het ML verdient.

\section{CONCLUSIE}

De toename van het aantal jongeren dat in aanmerking komt voor een Wajong-uitkering, maakt duidelijk dat het zeer gewenst is dat het kabinet beleid voert om te voorkomen dat steeds 
meer jongeren langdurig buiten het arbeidsproces komen te staan wegens ziekte of gebrek. Ook het kabinet onderkent dat de problematiek van toename van het aantal Wajongers en het kunnen inschakelen van jongeren met een beperking op de arbeidsmarkt zich niet beperkt tot het domein van UWV en het moment van de claimbeoordeling. In voorafgaande trajecten van Jeugdzorg en speciaal onderwijs zijn naar verwachting (meer) mogelijkheden om blijvende arbeidsongeschiktheid te voorkomen. Wanneer de aspirant Wajonger met UWV geconfronteerd wordt, zijn talloze momenten van mogelijke arbeidsoriëntatie al gepasseerd. Experts geven aan dat niet primair UWV deze kwestie kan en moet oplossen maar dat de sleutel in het onderwijs ligt. ${ }^{5} \mathrm{Nu}$ duidelijk is dat het speciaal onderwijs en praktijkonderwijs veelal eindonderwijs zijn, is het van belang dat in deze onderwijsvormen arbeidsoriëntatie een structureel leerdoel vormt. Dit is nog niet wettelijk geregeld zodat het van de individuele school afhangt of en hoe deze arbeidsoriëntatie is vormgegeven. ${ }^{\text {II }}$ Het onderwijs voor deze 'moeilijke' jongeren heeft ook nog een kwaliteitslag te maken (zie ook een recent rapport van de onderwijsinspectie ${ }^{12}$ ). In de Nederlandse pedagogische praktijk wordt er te weinig planmatig en resultaatgericht gekeken naar de mogelijkheden en wensen van de jongeren.

In de WIA wordt algemeen als één van de succesfactoren gezien dat werkgevers en werknemers verantwoordelijk zijn geworden voor het traject tot aan de WIA, dat ze de financiële gevolgen van langdurig verzuim ervaren en dat ze verantwoordelijk zijn voor de terugkeer in arbeid en daarop aangesproken (kunnen) worden door UWV. In de Wajong ontbreekt een dergelijk eenduidig traject en eenduidige verantwoordelijkheidsverdeling. Organisatienetwerken zijn zeer divers en wisselend van samenstelling. 'Hét landelijk organisatienetwerk rond jongeren met een arbeidshandicap of beperking bestaat niet'. ${ }^{\text {I3 }}$ Het kabinet ziet voor de centra voor jeugd en gezin een belangrijke schakel weggelegd maar dat moet nog ingevuld worden. Het kabinetsstreven is om reeds vanuit de schoolbanken de nadruk te leggen op arbeidsparticipatie en arbeidsmogelijkheden en minder op beperkingen. Ook met de nieuwe weten regelgeving voor de Wajong wil het kabinet meer de nadruk leggen op arbeidsmogelijkheden met de bijbehorende instrumenten en prikkels en minder op inkomensvoorziening wegens arbeidsongeschiktheid.

Belangrijke randvoorwaarde daarvoor is dat werkgevers arbeid beschikbaar stellen voor jon- geren met een beperking. Niet alleen arbeid als stage, als ze de school verlaten of op het moment dat de jongeren toegelaten zijn tot de Wajongwerkregeling. Voor duurzame participatie is het belangrijk dat werkgevers en jongeren blijven investeren in loopbanen en in passende arbeid. Of de plannen van het kabinet, 'vermindering administratieve last, CAO-afspraken en verbetering van een enkele voorziening' voldoende garantie bieden dat werkgevers aangepaste banen zullen creëren voor jongeren met beperkingen, is twijfelachtig. ${ }^{14}$ Aanvullend beleid gericht op het stimuleren van passende arbeid voor deze doelgroep bij reguliere bedrijven, bijvoorbeeld als een uitwerking van sociale economie, zal nodig zijn om meer Wajongers aan het werk te krijgen én te houden. ${ }^{15}$

In dit artikel heb ik mij gericht op enkele voorgenomen veranderingen in de Wajong die de verzekeringsartsen en arbeidsdeskundigen bij UWV raken. Veranderingen die UWV voor uitdagingen zal plaatsen bij de uitbreiding van de claimbeoordeling Wajong voor de Wajong-werkregeling. Bijvoorbeeld bij het vraagstuk hoe de omgeving van de Wajonger mee te wegen bij het beoordelen van arbeidsmogelijkheden nu en in de toekomst. Of het vraagstuk welke arbeid passend is voor een Wajonger. Veranderingen ook waarbij kantekeningen geplaatst kunnen worden omdat de fundamentelere onderbouwing nog ontbreekt en een bredere maatschappelijke discussie wenselijk is, mede omdat de kabinetsplannen een beperkte invulling lijken te zijn van het SERadvies over participatie mogelijkheden van jonggehandicapten. ${ }^{16}$ Het kabinetsvoornemen focust niet op het recht van jongeren met een beperking om zich te kunnen ontplooien in arbeid. Het focust op de verplichting om binnen de resterende mogelijkheden (enige) loonvormende arbeid te verrichten met als mogelijke sanctie dat iemand, van wie UWV eerst vaststelt dat hij/zij wegens ziekte of gebrek niet in staat is om minstens $75 \%$ van het minimumloon te verdienen, mogelijk geen inkomensondersteuning meer ontvangt van UWV. Daarmee tornt het kabinet enerzijds aan de Wajong als inkomensvoorziening op minimumniveau voor de jonggehandicapte. Anderzijds geeft het kabinet in haar plannen niet of nauwelijks invulling aan aanvullend beleid om jonggehandicapten optimaal te laten participeren in een vorm van werk die past bij hun mogelijkheden en talenten. Terwijl in het SER-advies handhaving van de Wajong als inkomensvoorziening op minimumniveau en optimale participatie in vormen van werk die passen 
bij hun mogelijkheden en talenten, juist centraal staan als primaire aanbeveling. ${ }^{16}$

\section{LITERATUUR}

I. Ministerie van SZW. Brief 'Participatie jongeren met een beperking' en bijlage 'Vergroting Participatie jongeren met een beperking'. Den Haag: ministerie van SZW, 30 mei 2008.

2. UWV. UWV kwartaalverkenning 2008-I. Amsterdam: UWV, 2008.

3. Besseling JJM, Hagen B, Andriessen S, et al. Toename gebruik ondersteuning voor jongeren met een gezondheidsbeperking. Werkdocument 385. Den Haag: ministerie van SZW, 2007.

4. UWV. UWV kwartaalverkenning 2006-III. Amsterdam: UWV, 2006.

5. Besseling JJM, Andriessen S, Vos EL de, Wevers CJ. Participatiemogelijkheden van Wajongers. Hoofddorp: TNO, 2008

6. Berendsen E, Havinga H, Stoutjesdijk M. De participatiemogelijkheden van de Wajonginstroom. UWVkenniscahier 08-or. Amsterdam: UWV, 2008.

7. Aarts L, Hout C van, Thijs C, Visscher K. Evaluatie jobcoaching. Den Haag: APE, 2008.

8. Smitskam CJ, Vos EL de. Re-integratie-instrumenten voor arbeidsgehandicapten. PS-special 2007-4. Deventer: Kluwer, 2007.

9. Veen A van der. Aboutaleb verdedigt horigheid. Volkskrant 2 I juli 2008.
Io. Bukman M, et al. Werk moet lonen. Utrecht: CG-raad, 2008.

I I. Bakker RC, Visser SM de, Velzen JH van, et al. Hobbels en kruiwagens. Knelpunten en succesfactoren bij de overgang van school naar werk door Wajongers. Zoetermeer: Research voor Beleid, maart 2008.

I2. Inspectie van het Onderwijs. Cluster 3. De kwaliteit van het onderwijs in cluster 3. Utrecht: Inspectie van het Onderwijs, mei 2008.

I3. Paul J. Organisatienetwerken rond jongeren met een arbeidshandicap of beperking. Nieuwegein: CrossOver, 2008

I4. CG-raad. Eerste reactie op kabinetsstandpunt Wajong d.d. 30 mei 2008. Utrecht: CG-raad, 2 juni 2008.

I5. Smit A, Genabeek J, Klerkx M. Europese ervaringen met sociale economie; werk voor gehandicapten en langdurig werklozen in sociale ondernemingen. Hoofddorp: TNO, 2008.

I6. SER. Meedoen zonder beperkingen. Meer participatiemogelijkheden voor jonggehandicapten. Den Haag: SER, 2007.

\section{PERSONALIA}

J.J.M. Besseling werkt als senior-onderzoeker/adviseur bij TNO Kwaliteit van Leven.

\section{CORRESPONDENTIEADRES}

E-mail: jan.besseling@tno.nl. 